\title{
Absorption of sunlight by dust as inferred from satellite and ground-based remote sensing
}

\author{
Y.J. Kaufman \\ NASA Goddard Space Flight Center, Greenbelt Maryland 20771 \\ Didier Tanré \\ Lab. d'Optique Atmos., CNRS, Univ. de Sciences et Techniques de Lille, Villeneuve d'Ascq, France \\ O. Dubovik \\ Science Systems and Applications, Inc., Lanham, MD 20706
}

\author{
A. Karnieli \\ J. Blaustein Inst. for Desert Research, Ben Gurion Univ., Sede-Boker, Israel 84990
}

L. A. Remer

NASA Goddard Space Flight Center, Greenbelt Maryland 20771

\begin{abstract}
Dust absorption of solar radiation is not well known due to limitations in the accuracy of in situ measurements. Here we report two new independent remote sensing techniques that provide sensitive measurements of dust absorption. One uses satellite spectral measurements, the second ground based sky measurements. Both techniques demonstrate that Saharan dust absorption of solar radiation is several times smaller than the current international standards. For example, at wavelength of $0.64 \mu \mathrm{m}$ the dust single scattering albedo is reported here as $0.97 \pm 0.02$ rather than $0.87 \pm 0.04$ in recent review.
\end{abstract}

\section{Introduction}

Dust is a dominant feature of global aerosol system [Prospero, 1981]. Dust absorbs solar radiation and scatters it to space. The balance between dust absorption and scattering [Fraser and Kaufman, 1985] determines its ability to counteract greenhouse warming and to affect atmospheric heating rates [Alpert et al., 1998] and cloud formation. Presently dust absorption is highly uncertain [Sokolik and Toon, 1996].

Dust absorption expressed by its imaginary index of refraction, $\mathrm{n}_{\mathrm{i}}$, is recommended by the World Meteorological Organization (WMO) to be: $n_{j}=0.008$ [WMO, 1983]. It corresponds to single scattering albedo (ratio of scattering to scattering + absorption) of $\omega_{0}=0.63$ at $\lambda=0.5 \mu \mathrm{m}$. A smaller imaginary index was reported by Levin et al. [1980]: $n_{i}=0.003$ $\left(\omega_{0} \sim 0.87\right)$ for heavy dust. A moderate change in the single scattering albedo from 0.95 to 0.85 can change its radiative forcing from negative to positive [Hansen et al., 1997]. In the blue and UV parts of the spectrum iron compounds absorb sunlight, however absorption in the visible, longward of $0.5 \mu \mathrm{m}$ is

Copyright 2001 by the American Geophysical Union.

Paper number 2000GL012647.

0094-8276/01/2000GL012647\$05.00 most likely the result of black carbon absorption originating from pollution sources [Lindberg, 1975] and transported with the dust.

The high absorption associated with Saharan dust, stands in contrast to radiation measurements: Fouquart et al. [1986] using flux divergence measurements from aircraft over Africa derived single scattering of $\omega_{0}=0.95$ for the broad solar radiation. Analysis of Landsat data over the Persian Gulf shows imaginary index indistinguishable from zero [Otterman et al 1975]. We report that well characterized spectral radiometers, one observing from space and the other from the ground, can provide two independent non-intrusive and accurate remote sensing measurements of dust absorption in the entire atmospheric column.

\section{Analysis}

The satellite remote sensing method is illustrated in Fig. 1. For dark surfaces (ocean) dust increases the apparent reflectance of the earth + atmosphere system by backscattering solar radiation to space for both values of $\omega_{0}$. For bright surfaces (reflectance $\geq 0.25$ ) the effect of $\omega_{0}$ is stronger and surface brightness determines whether dust increases (high $\omega_{0}$ ) or decreases (low $\omega_{0}$ ) the apparent reflectance [Kaufman, 1987]. Over a bright surface, satellites measure the balance between dust scattering to space and absorption of the direct and reflected solar radiation; thus, like a laboratory scale, satellites provide a precise measure of the dust $\omega_{0}$.

Dust backscattering depends on the particle size. Size distributions derived from sky aureole measurements by the AErosol RObotic NETwork (AERONET [Holben et al., 1998]) in Capo Verde, west of the Sahara and Sede Boker, Israel, east of the Sahara, during 1995-1998 show that dust particles are in the coarse mode with effective radius between 1.5 and $2.5 \mu \mathrm{m}$. AERONET measurements of Asian dust arriving across the Pacific Ocean to San Nicholas Island, off the west-coast of US, show effective radius of $1.5 \mu \mathrm{m}$. Similar results were reported from aircraft measurements [Talbot et al., 1986] and were used in models [Tegen et al., 1996]. In Capo Verde, a smaller coarse mode, $0.4-0.5 \mu \mathrm{m}$, is also detected though with much smaller 


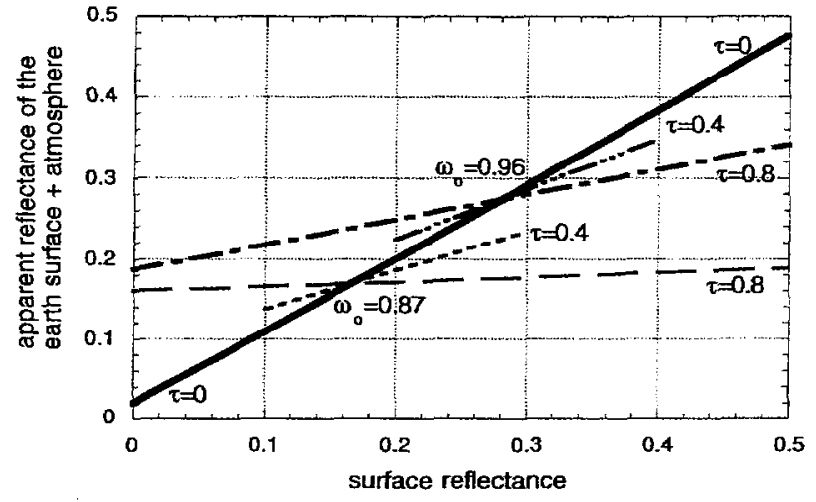

Figure 1. Calculated reflectance of the earth surface + atmosphere observed at nadir $\left(\lambda=0.66 \mu \mathrm{m}, \theta_{0}=32^{\circ}\right)$. Solid blue line - no dust $(\tau=0)$ only molecular scattering, broken lines - dust with low, $\omega_{0}=0.96$ (green), and high, $\omega_{0}=0.87$ (red) absorption respectively. Optical thickness, $\tau$, of 0.4 and 0.8 is indicated.

volume. Therefore, a range of effective radii of $1.5-2.5 \mu \mathrm{m}$ is chosen in this analysis.

Dust absorption is derived from simultaneous Landsat images and sunphotometer measurements in Senegal [Tanré et al., 1988] in cloud free regions. Figure 2 shows two Landsat images used in the analysis. The view direction is close to nadir and the solar zenith angle is $32^{\circ}$, resulting in scattering angle around $148^{\circ}$, at which we do not expect significant effects of particle nonsphericity [Nakajima et al., 1989]. The images (Fig $2 \mathrm{~A}$ and B) and plots of the apparent reflectance (Fig 2C) indicate that the entire land area became much brighter due to the presence of heavy dust. The difference in the spectral brightness between the two images (see Fig. $3 \mathrm{~A}$ ) in the vicinity ( $3 \mathrm{~km}$ radius) of the sunphotometer is used to derive the dust absorption and single scattering albedo: First the surface spectral reflectance is derived from the radiance measured in the less dusty day for the given $\tau_{64}=0.8$. Second, the surface reflectance is used to compute the radiance at satellite level in the hazy day for the measured optical thickness, $\tau_{64}=2.4$. Both steps are repeated independently for each wavelength, for the two assumed particles sizes and for several values of the imaginary index, until a fit to the measurements is reached. No spectral dependence of the surface reflectance or aerosol properties is assumed. The result is the spectral dust single scattering albedo derived consistently from the two satellite images, for each option of the effective radius (1.5 and $2.5 \mu \mathrm{m})$.

The large increase in the earth-surface reflectance of 0.06 (see Fig. $2 \mathrm{C}$ and $3 \mathrm{~A}$ ), due to the presence of dust, suggests close to zero absorption $\left(\omega_{0} \sim 1\right)$ for $\lambda>0.5 \mu \mathrm{m}$. Even an imaginary index of $n_{i}=0.004$, half of the WMO value, would cause a decrease rather than increase in the apparent reflectance (Fig 3A). The spectral single scattering albedo derived from the radiance difference is shown in Fig. 3B. Uncertainty in the effective radius $(1.5 \mu \mathrm{m}$ vs. $2.5 \mu \mathrm{m})$ or in the real part of the refractive index (1.53 vs. 1.46$)$ results in uncertainty of only $\Delta n_{j}= \pm 0.0005$ in the imaginary index or $\Delta \omega_{O}= \pm 0.005$ (Fig. 3B). The results are compared in the figure with the literature. Note that while absorption in the blue channels is expected due to the presence of iron oxides in hematites, the small absorption at $1.65 \mu \mathrm{m}$ is surprising and within the present accuracy limits; however, similar absorption has been already found in the spectra of Mars, due to mineral-hydrate mixtures [Bell and McCord, 1989].

What other sources of errors can affect the satellite analysis? Surface angular effects are expected to be negligible for the nadir view [Lee and Kaufman, 1986]. Landsat calibration error of $10 \%$
[Markham and Barker, 1985] can cause an error of only $\Delta \omega_{0}= \pm 0.01$, since dust absorption is derived from the difference between the dusty and the less dusty day. The uncertainty in the

A) May 3, 1987
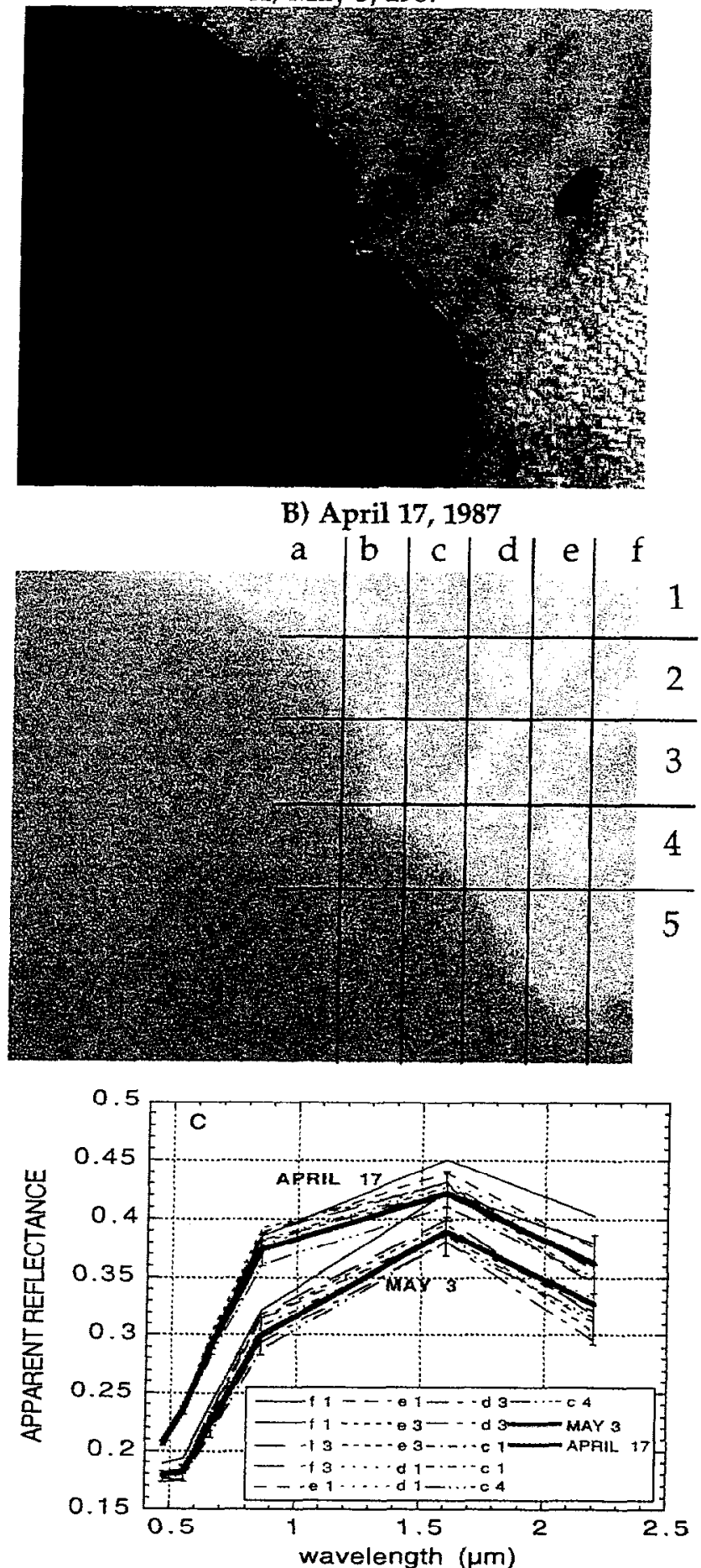

Figure 2. Landsat TM images of dust over the coast of Senegal. A) image for May 3, 1987 (less dust, $\tau_{64}=0.8$ ) and (B) April 17, 1987 (heavy dust, $\tau_{64}=2.4$ ). Color scale: $0.49 \mu \mathrm{m}$ (blue), $0.55 \mu \mathrm{m}$ (green) and $0.66 \mu \mathrm{m}$ (red). C) spectral apparent reflectance for the less dusty (green) and very dusty (red) days for 8 grid points as indicated (raw and column) in the image. The solid-heavy lines are the average values for the entire land area, given with the standard deviations. Note the systematic increase in the image brightness in all the grid boxes from the less dusty to heavy dust day. 

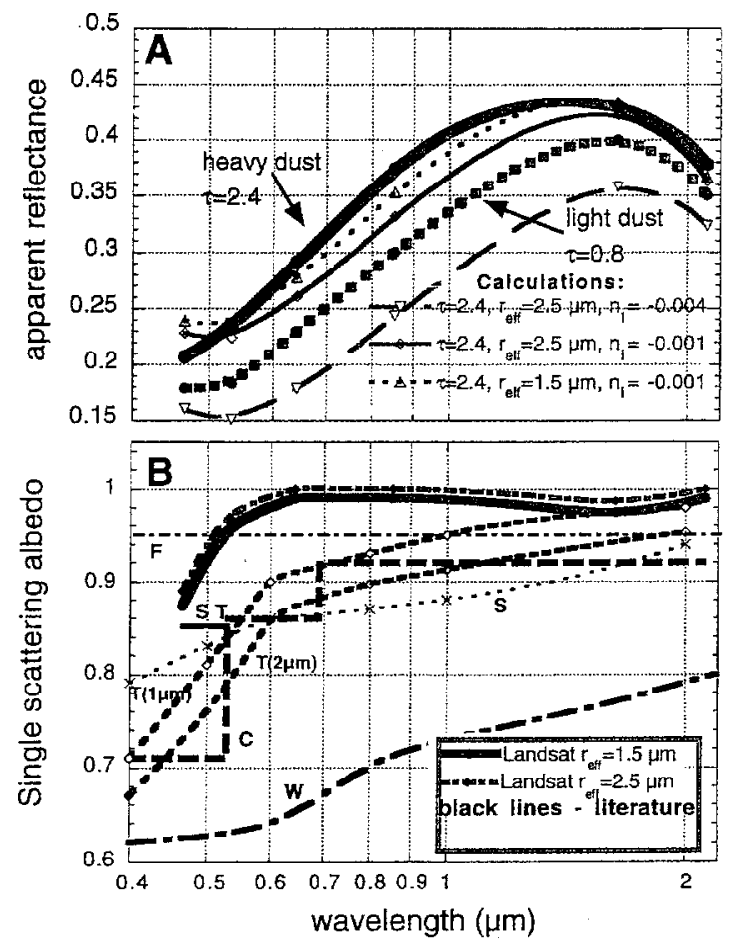

Figure 3. (A): Apparent reflectance at the top of the atmosphere over the desert in Senegal measured by Landsat TM (heavy green lines) for $\tau=0.8$ (dashed) and 2.4 (solid). The measurements are compared with calculations (thin lines) for imaginary refractive indices, $n_{i}$, and effective radius, $r_{e f f}$, given in the caption. (B): The spectral single scattering albedo, $\omega_{0}$, for $r_{e f f}=1.5$ and $2.5 \mu \mathrm{m}$ (green lines), that fit the change in the brightness in A. Comparison with the literature: F - Fouquart et al. [1986], WWMO [1983], T $(1 \mu \mathrm{m})$ and $\mathrm{T}(2 \mu \mathrm{m})$ - Tegen et al. [1996] for $1 \mu \mathrm{m}$ and $2 \mu \mathrm{m}$ effective radius respectively, C - Carlson and Benjamin [1980], ST - Sokolik and Toon [1996].

dust elevation of $\pm 2 \mathrm{kms}$, based on radiative transfer calculations, can introduce errors only in channels with strong molecular scattering, e.g. the $0.49 \mu \mathrm{m}$ of $\Delta \omega_{\mathrm{O}}= \pm 0.01$. The overall error in the derived single scattering albedo is $\Delta \omega_{0}= \pm 0.02$, except in the blue where it is $\Delta \omega_{0}= \pm 0.03$.

Independent of the satellite data, a new inversion technique [Dubovik et al., 2000] is applied to AERONET measurements in Capo Verde in June-August 1999 to derive the single scattering albedo. The inversion technique finds simultaneously the best fitting aerosol size distribution (Fig 4B), single scattering albedo (Fig. 4A) and refractive index to the scattered sky radiances and extinction of sunlight. All AERONET data were selected for periods of time with the lowest measurement uncertainty (better than $\pm 5 \%$ ), high dust concentrations ( $\tau_{64}>0.4$ and dominance of the coarse mode). The expected uncertainty in the single scattering albedo is $\Delta \omega_{0}= \pm 0.03$, mainly due to uncertainty in the calibration. A change in the imaginary index to $0.004\left(\omega_{0}=0.83\right.$ at $0.64 \mu \mathrm{m}$ ), increases the retrieval error 3 times and reduced the sky brightness by $17 \%$ well beyond the method uncertainty. The results in Fig. $4 \mathrm{~A}$ show that the single scattering albedo in the blue channel is higher by 0.03 for the AERONET analysis, and in the red to near infrared (NIR) it is lower by 0.05 to 0.02 respectively, than the satellite retricval. Though this difference could be attributed to combination of the measurement uncertainties, it is interesting to note the trend in the AERONET single scattering albedo with the optical thickness. This trend extrapolates linearly to values similar to the satcllite analysis derived from the higher optical thickness. Change in the single scattering albedo from dusty to very dusty or dust storm conditions can happen if the additional larger particles lifted by the stronger winds have smaller iron concentration. We calculated the uncertainty in the extrapolation by using a "boot strap" technique. The error bar on the extrapolations is the range of variation of the boot strap calculated slopes using a different selection of the measurements points (e.g. with and without the extreme values).

\section{Conclusions}

In this paper, two new independent remote sensing techniques were used to determine the dust absorption. One is based on two coordinated satellite spectral images with large difference in the dust column concentration; the second on sky measurements from a ground based radiometer. Despite 12 years difference in their application, both techniques agree that absorption of
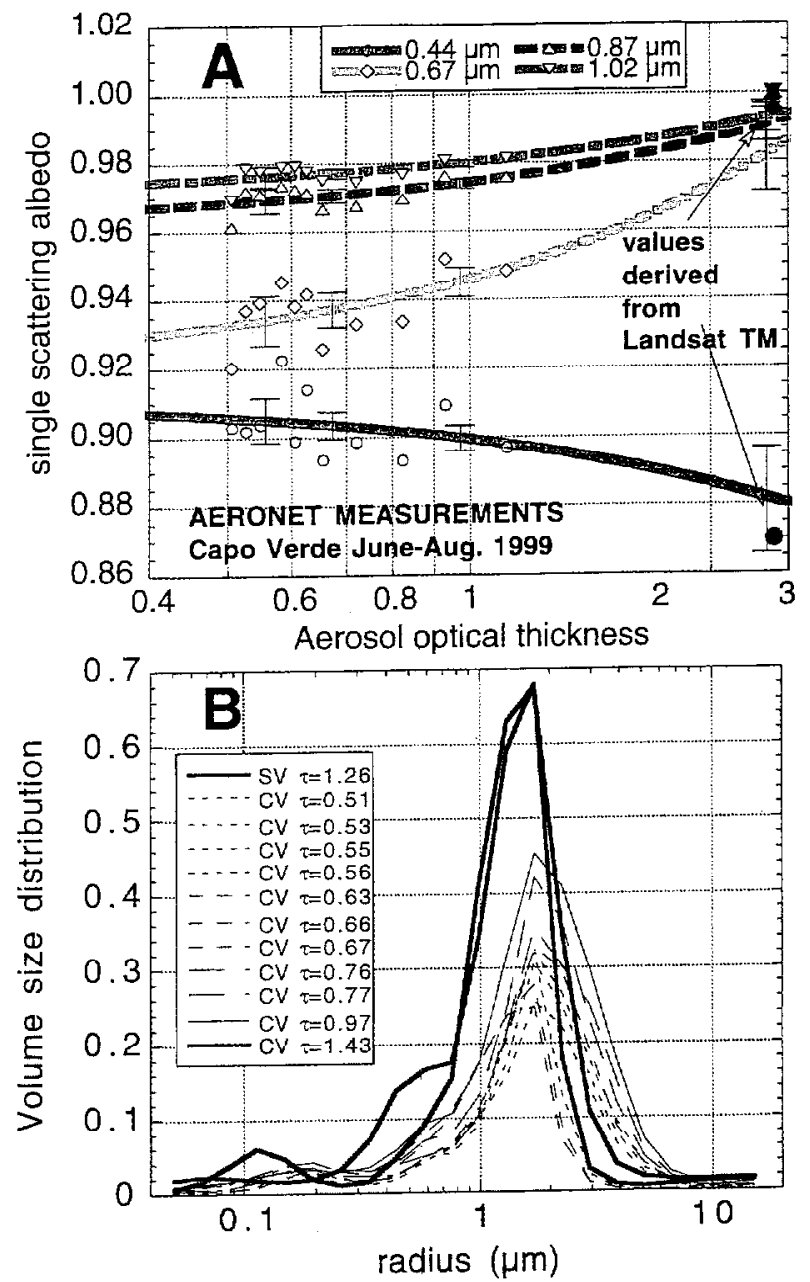

Figure 4. (A) Comparison between the single scattering albedo, $\omega_{0}$, derived from Landsat TM images over Senegal in 1987 (full symbols) and $\omega_{0}$ derived from the AERONET sun/sky radiometers solar almucantar measurements (empty symbols). To compare the two methods, linear fits (color lines) were performed to the AERONET data and extrapolated to the Landsat optical thickness. The uncertainty in the fit is calculated using a "bootstrap tcchnique" and shown by the bars in the figure. (B): The volume size distribution of the dust, measured by AERONET, indicates dominance by large dust particles. CVCapo Verde, SV-Solar Village, $\tau$, dust optical thickness. 
sunlight by dust from Africa over the Atlantic Ocean is significantly lower than presently measured in situ and used in climate models. Hansen et al. [1997] showed that when cloud feedbacks are included in the radiative forcing analysis, aerosol single scattering albedo smaller than $\omega_{0}=0.91$ leads to warming and a higher values to a cooling of the climate system. While the cited literature in Fig. 3 corresponds to $\omega_{0}<<0.9$, indicating that dust should heat the climate system, the new findings show $\omega_{0} \gg 0.9$ for most of the solar spectrum indicating cooling of the climate system. These new values of dust single scattering albedo correspond to the upper limit of the uncertainty range of Sokolik and Toon [1996] and would increase significantly the cooling effect of dust. Thermal radiation emitted from the earth surface may be responsible for part of the heating observed by Alpert et al. [1998] within the aerosol layer. It is possible that many of the in situ measurements that reported higher absorption, measured a mixture of dust with absorbing aerosol. This may be true in particular when the dust is transported over heavily populated areas like in East Asia.

Acknowledgments. The AERONET sunphotometer/ radiometer data were provided by Brent N. Holben from GSFC, Robert Frouin from Scripps, F. Lavenu from CESBIO/CNES/CNRS in Toulouse and B. Chatenet from LISA/Universités Paris 7 and 12. We wish to express our gratitude to M. Santos Soares, Director of the Servico National de Meteorologia E Geophysica (SNMG), Cap Verde, for his help in maintaining the Capo Verde AERONET instrument.

\section{References}

Alpert, P., Y. J. Kaufman, Y. Shay-El, D. Tanre, A. da Silva, S. Schubert, Y. H. Joseph, Quantification of Dust-Forced heating of the Lower Troposphere., Nature, 395, 367-370, 1998.

Bell, J. F, and T.B. McCord, Mars- near IR comparative spectroscopy during the 1986 opposition, Icarus, 77, 21-34, 1989.

Carlson, T.N. and S.G., Benjamin, Radiative heating rates of Saharan dust, J. Atmos. Sci., 37, 193-213, 1980

Dubovik, O., A. Smirnov, B.N. Holben, M.D. King, Y. J. Kaufman, T.F. Eck and I. Slutsker, Accuracy assessment of aerosol optical properties retrieval from AERONET sun and sky radiance measurements, $J$. Geophys. Res 105, 9791-9806, 2000.

Hansen, J., Sato and Ruedy, Radiative forcing and climate response, J. Geophys. Res, 102, 6831-6864, 1997.

Holben, B.N., T.F. Eck, I. Slutsker, D. Tanré, J.P. Buis, A. Setzer, E. Vermote, J.A. Reagan, Y.J. Kaufman, T. Nakajima, F. Lavenu, I. Jankowiak and A. Smimov, AERONET-A federated instrument network and data archive for aerosol characterization, Rem. Sens. of the Environ., 66, 1-16, 1998.

Fouquart, Y., B. Bonnel, J. C. Brogniez, L. Buriez, L. Smith and J. J. Morcrette, Observations of Saharan aerosols: Results of ECLATS Field experiment. II: Broadband radiative characteristics of the aerosols and vertical radiative flux divergence, J. Climate and Appl. Meteor., 25, 28-37, 1986.

Fraser, R.S. and Y.J. Kaufman, The Relative Importance of Aerosol Scattering and Absorption in Remote Sensing, IEEE J. Geosc. Rem. Sens., GE-23, 525-633, 1985.

Kaufman, Y.J., Satellite Sensing of Aerosol Absorption, $J$. Geoph. Res., 92, 4307-4317, 1987.

Lee, T. and Y. J. Kaufman, The Effect of Surface NonLambertianity on Remote Sensing of Ground Reflectance and Vegetation Index, IEEE $J$. Geosci. Rem. Sens., GE-24, 699 $708,1986$.

Levin, Z., J.H. Joseph and Y. Mekler, Properties of Sharav (Khamsin) dust - comparison of optical and direct sampling data, J. Atmos. Sci., 37, 882-891, 1980.

Lindberg, J.D., The composition and optical absorption coefficient of atmospheric particulate matter, Opt. Quantum Electron., 7, 131-139, 1975.

Markham, B.L. and J. L. Barker, Spectral characterization of the Landsat TM sensors, Int. J. Rem. Sens., 6, 697-716, 1985.

Nakajima, T., M. Tanaka, M. Yamano, M. Shiobara, K. Arao and Y. Nakanishi, Aerosol optical characteristics in the yellow sand events observed in May, 1982 at Nagasaki-Part 2 Models, J. Meteor. Soc. of Japan, 67, 279-291, 1989;

Otterman, J., R. S. Fraser and O.P. Bahethi, Characterization of tropospheric desert aerosols at solar wavelengths by multispectral radiometry from Landsat, $J$. Geoph. Res., 87, 1270-1278, 1982.

Prospero, J.M., Eolian transport to the world ocean, The sea, Vol VII, The Oceanic Lithosphere, Ed. C. Emiliani, Wiley, NewYork, 801-874, 1981.

Sokolik, I.N. and O.B. Toon, Direct radiative forcing by anthropogenic airborne mineral aerosol, Nature, 381, 681$683,1996$.

Talbot, R.W., R.C. Harris, E.V. Browell, G.L. Gregory, D.I. Sebacher and S.M. Beck, Distribution and geochemistry of aerosols in the tropical North Atlantic troposphere, relationship to Saharan dust, J. Geophys. Res., 91, 5173-5182.

Tanré D., P.Y. Deschamps, C. Devaux, M. Herman, Estimation of Saharan aerosol optical thickness from blurring effects in Thematic Mapper data, J. Geophys. Res., 93, 15955-15964, 1988.

Tegen, I., A.A. Lacis and I. Fung, The influence on climate forcing of mineral aerosols from disturbed soils, Nature, 380 419-422, 1996.

WMO, 1983: Radiation commission of IAMAP meeting of experts on aerosol and their climatic effects, WCP55, Williamsburg VA, 28-30, 1983.

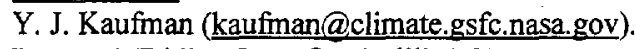

D. Tanré (Didier.Tanre@univ-lille1.fr)

O. Dubovik (dubovik@aeronet.gsfc.nasa.gov)

A. Karnieli (kamieli@bgumail.bgu.ac.il)

L. A. Remer (Remer@climate.gsfc.nasa.gov)

(Received: November 16, 2000; Revised: December 26, 2000; Accepted: January 17, 2001.) 